Return to the Manage Active Submissions page at http://spie.org/app/submissions/tasks.aspx and approve or disapprove this submission. Your manuscript will not be published without this approval. Please contact author_help@spie.org with any questions or concerns.

\title{
Multitemporal evaluation of topographic correction algorithms using synthetic images
}

\author{
I. Sola*, M. González de Audícana, J. Álvarez-Mozos, J.L. Torres \\ Department of Projects and Rural Engineering. Public University of Navarre (UPNA), \\ Campus Arrosadía. Edificio Los Olivos 31016 Pamplona-Iruñea.
}

Land cover classification and quantitative analysis of multispectral data in mountainous regions is considerably hampered by the influence of topography on the spectral response pattern. In the last years, different topographic correction (TOC) algorithms have been proposed to correct illumination differences between sunny and shaded areas observed by optical remote sensors. Although the available number of TOC methods is high, the evaluation of their performance usually relies on the existence of precise land cover information, and a standardised and objective evaluation procedure has not been proposed yet. Besides, previous TOC assessment studies only considered a limited set of illumination conditions, normally assuming favourable illumination conditions. This paper presents a multitemporal evaluation of TOC methods based on synthetically generated images in order to evaluate the influence of solar angles on the performance of TOC methods. These synthetic images represent the radiance an optical sensor would receive under specific geometric and temporal acquisition conditions and assuming a certain land-cover type. A method for creating synthetic images using state-of-the-art irradiance models has been tested for different periods of the year, which entails a variety of solar angles. Considering the real topography of a specific area a Synthetic Real image (SR) is obtained, and considering the relief of this area as being completely flat a Synthetic Horizontal image (SH) is obtained. The comparison between the corrected image obtained applying a TOC method to a SR image and the SH image of the same area, i.e. considered the ideal correction, allows assessing the performance of each TOC algorithm. This performance is quantitatively measured through the widely accepted Structural Similarity Index (SSIM) on four selected TOC methods, assessing their behaviour over the year. Among them, C- Correction has ranked first, giving satisfying results in the majority of the cases, while other algorithms show a good performance in summer but give worse results in winter.

Keywords: Synthetic image, topographic normalization, multitemporal evaluation, SSIM, TOC, DEM

*sola.69407@unavarra.es Tel.: +34 - 948169000 Fax: +34 - 948169169 
Return to the Manage Active Submissions page at http://spie.org/app/submissions/tasks.aspx and approve or disapprove this submission. Your manuscript will not be published without this approval. Please contact author_help@spie.org with any questions or concerns.

\section{INTRODUCTION}

The irradiance impinging on a certain point at the Earth surface depends on the solar zenith and azimuth angles, as well as on the slope and aspect of the terrain, which determine the solar incidence angle $\left(\gamma_{i}\right)$ between the sun rays and the normal to the ground. Differences in the solar incidence angle, i.e. differences in the solar illumination, normally result in variations in the radiance detected by remote sensors between areas with similar land cover and biophysical-structural properties [1]. This effect can adversely affect the usefulness of remote sensing data for different applications, such as Land-Use/Land-Cover mapping, vegetation cover monitoring, change detection or biophysical parameter estimation, particularly in mountainous areas [2-6]. The objective of Topographic Correction (TOC) methods is to compensate the differences in radiance between sunny and shaded areas caused by variations on the shape and aspect of terrain.

The topographic effect has a significant impact on the quantitative analysis of remotely sensed data [7]. During the last two decades, several procedures were proposed to correct or attenuate it. Most of these procedures require the computation of the illumination conditions of the area to be corrected [1,2, 8-11]. TOC methods can be grouped into two subcategories, Lambertian methods (LTOC), and non-Lambertian methods (NLTOC), depending on whether they assume reflectance as being independent or not on observation and incidence angles. LTOC methods assume the incident radiation as being reflected in all directions equally. Besides, they only model the direct portion of the irradiance, even if areas under low illumination conditions get a considerable amount of diffuse irradiance. To account for the shortcomings of these unrealistic assumptions, several semi-empiric non-Lambertian methods have been developed including band dependent parameters, i.e., the Minnaert correction method $[2,12]$ and the C-correction method [2]. The former includes a constant modelling of the non-Lambertian behaviour of each land cover for every band. The latter introduces, in order to emulate the effect of diffuse irradiance from the sky, a parameter $\mathrm{C}$, which is the ratio between the slope and intercept of the linear regression equation between the radiance of each band and $\cos \gamma_{i}$. Alternatively, purely empiric approaches have also been proposed, i.e., the Empirical-Statistical method of Teillet [2], which assumes a linear relationship between the radiance of each band and the cosine of the solar incidence angle.

An essential point, necessary to evaluate objectively and accurately the different topographic correction methods, is the analysis of the quality of the corrected images. With this aim, traditionally an evaluation based on the visual assessment of the removal of the topographic effect in satellite imagery has been proposed [8, 13-15]. This approach gives a good first indication on the quality of the correction. However, it is indeed subjective and the assessment strongly depends on the skill of the observer. More objective and rigorous assessments have been proposed in the literature, i.e., the quantification of the reduction of the dependence between $\cos \gamma_{\mathrm{i}}$ and the radiance of each spectral band after the correction [16], the analysis of the variations in the radiometry of the corrected scenes [8], the reduction of the land cover class variability $[7,10,17]$, the improvement on classification accuracy after topographic correction $[2,15]$ the improvement in biophysical parameter retrievals $[3,4]$ or the increase in temporal stability of a time series for individual pixels [18].

These evaluation procedures have their own limitations, i.e. the need for a priori knowledge on structural landscape characteristics [11]. This information is normally not available. In fact, this is the type of information pursued from the images to be corrected. Due to this, different evaluation studies published in the recent years did not agree on which TOC method performs the best in every situation. To overcome this problem in this study the performance of TOC methods has been assessed by using synthetic images, which represent the radiance an optical sensor would receive under specific geometric and temporal acquisition conditions, considering a certain land-cover structure and assuming several simplifications. The aim of this paper is to analyze the behaviour of four selected TOC methods during the year. With this purpose, a set of six different temporal configurations have been selected to simulate synthetic scenes acquired along the year.

Synthetic images can be generated considering the real topography of a specific area (Synthetic Real image, SR), or considering a perfectly flat surface (Synthetic Horizontal image, SH). The latter is, in fact, the image that should ideally be obtained after successfully removing the topographic effect from the Synthetic Real image. The comparison between the corrected image obtained applying a TOC method to a SR image and the SH image of the same area, provides a means for objectively assessing the accuracy of the TOC method applied. The Structural Similarity Index (SSIM), proposed by Wang et al. [19] is applied for that purpose.

8537 - 5 V. 3 (p.2 of 11) / Color: No / Format: A4 / Date: 8/30/2012 2:43:59 AM

SPIE USE: DB Check, Prod Check, Notes: 
Return to the Manage Active Submissions page at http://spie.org/app/submissions/tasks.aspx and approve or disapprove this submission. Your manuscript will not be published without this approval. Please contact author_help@spie.org with any questions or concerns.

Most of the evaluations of TOC methods presented in the literature were applied under specific and generally favourable conditions, i.e. just for a certain platform and usually in summer months. In this work though, six different temporal configurations, that is, six different solar positions are considered. These configurations are representative of different illumination conditions. Therefore, the influence of date and time on the behaviour of TOC methods can be explored.

\section{SYNTHETIC IMAGE GENERATION}

The process to simulate a synthetic image for a specific area, explained by Sola et al.[20], can be summarized in two phases. On the first phase, the image representing the global irradiance at each point of the area of interest at a certain date and time is obtained. On the second phase, the top-of-atmosphere radiance (TOARD) a sensor would receive is generated, considering a certain sensor configuration. This is in fact, the final synthetic image.

Firstly, it is necessary to estimate the Global Horizontal Irradiance $\left(E_{e, g}\right)$, i.e., the total amount of direct and diffuse radiation reaching the Earth surface, considering it horizontal, in cloudless conditions. Several models can be used to estimate $E_{e, g}$ and its diffuse and direct components [21-24]. In this work the Cloud-free Global Radiation model [25-28] is used. This model was validated using 25 test sites spread across Europe within the SATEL-LIGHT project [29]. It showed a good correspondence between estimated and measured values under sunny or quasi sunny conditions.

Obviously, the topography of Earth surface areas is normally non-flat, being necessary to consider the specific geometrical or topographical characteristics of each area. To compute the Global Tilted Irradiance $\left(E_{\beta, g}\right)$, it is necessary to take into account not only the Direct Tilted Irradiance or Sunlight $\left(E_{\beta, s}\right)$, but also the Ground-Reflected Irradiance $\left(E_{\beta, r}\right)$ as well as the Sky Diffuse Irradiance or Skylight $\left(E_{\beta, d}\right) . E_{\beta, s}$ is calculated applying the cosine law to Direct Horizontal Irradiance. The effect of surrounding topography on direct radiation is modelled by adding a binary factor to control cast shadows proposed by Richter [30]. $E_{\beta, d}$ is calculated with Hay's Model [31], also enhanced with the binary factor proposed by Richter. Finally, Ground-Reflected Irradiance $\left(E_{\beta, r}\right)$, is calculated through the method proposed by Sandmeier [32] by considering, among other factors, the portion of adjacent terrain seen from a surface, so-called Terrain View Factor.

On the second phase, it is necessary to consider the previously obtained Global Tilted Irradiance as well as land-covers' reflectance, the orbital and observational configuration of the sensor, i.e., sensor viewing angle, spatial resolution of the sensor and acquisition time. The at-sensor radiance values can be calculated using the following expression:

$$
L=L_{p}+\frac{\rho \cdot T_{u} \cdot E_{\beta, g}}{\pi}
$$

where, $L_{p}$ is the atmospheric path radiance calculated with Bird and Hulstrom's model [33], $\rho$ is the land-cover reflectance value, $T_{u}$ is the upward atmospheric transmittance, obtained through the expression proposed by Gilabert [34], and $E_{\beta, g}$ is the Global Irradiance reaching each pixel. Further details on the synthetic image generation method can be found on Sola et al. [35].

\section{TOC ALGORITHMS}

Four TOC algorithms have been selected in this work, as they are frequently used in the literature and their differences will provide contrasting results for discussing the utility of synthetic imagery. Besides, they are representative of different categories of topographic correction methods proposed over the last decades. One of the selected TOC is the Cosine method, which is the simplest and one of the most widely used Lambertian TOC (LTOC), originally proposed by Smith et al. [12] and later modified by Teillet [2]. Also the Minnaert correction method [2, 12,36] and the C-correction method [2] have been tested, which are semi-empiric non-Lambertian methods (NLTOC) including band dependent parameters. Finally a purely empiric approach, the Empirical-Statistical method, also proposed by Teillet [2], has been evaluated in this work. In any case, the aim of this work is not to compare different TOC methods, but to obtain a preliminary knowledge of the behaviour of TOC methods across the year, comparing winter and summer scenes. 
Return to the Manage Active Submissions page at http://spie.org/app/submissions/tasks.aspx and approve or disapprove this submission. Your manuscript will not be published without this approval. Please contact author_help@spie.org with any questions or concerns.

\begin{tabular}{|cc|}
\hline Table 1. Equations of the TOC methods tested \\
\hline TOC METHOD & $\boldsymbol{E Q U A T I O N}$ \\
\hline COSINE & $L_{\text {corr }}=L \cdot \frac{\operatorname{COS}\left(\theta_{s}\right)}{\operatorname{COS}\left(\gamma_{i}\right)}$ \\
C-CORRECTION & $L_{\text {corr }}=L \cdot \frac{\operatorname{COS}\left(\theta_{s}\right)+C}{\operatorname{COS}\left(\gamma_{i}\right)+C}$ \\
ENHANCED MINNAERT & $L_{\text {corr }}=L \cdot\left[\frac{\operatorname{COS}^{k}\left(\theta_{s}\right)}{\operatorname{COS}\left(\gamma_{i}\right)^{k} \cdot \operatorname{COS}(\beta)^{k-1}}\right]$ \\
EMPIRIC-STATISTICAL & $L_{\text {corr }}=L-\left(A+B \cdot \operatorname{COS}\left(\gamma_{i}\right)\right)+L_{\text {mean }}$ \\
\hline
\end{tabular}

where, $L_{c o r r}$ and $L$ are, respectively TOC-corrected and non-corrected at-sensor radiance, $\theta_{s}$ is the solar zenith angle, $\gamma_{i}$ is the solar incidence angle, $\beta$ is the terrain slope, $A$ and $B$ are, respectively, the intercept and the slope of the regression line between radiance and illumination, i.e. $\operatorname{COS}\left(\gamma_{i}\right)$, and $k$ and $C$ are empiric constants calculated for each method as described by Teillet et al. [2].

A limitation of this study is that TOC methods have been applied to the complete scene, without any previous stratification of land covers. It is well-known that stratified TOC methods yield better results, but this study is focused on the multitemporal evaluation of TOC methods, and not on an accurate comparison of their performance.

\section{STRUCTURAL SIMILARITY INDEX (SSIM)}

The synthetic image generated considering flat topography $(\mathrm{SH})$ corresponds to the ideal TOC correction, when the topographic distortions disappear entirely. In order to measure the similarity between this ideal image SH and the TOC corrected SR images, the Structural Similarity Index (SSIM) is used. The SSIM is an universal, objective and widely accepted image quality index; proposed by Wang et al. [19]. Its computation is straightforward and, besides, it is useful for different image processing applications, e.g., image compression, algorithm optimization, etc. The SSIM considers three elements: Luminance comparison, contrast distortion and structural similarity; for comparing an ideal reference image (in our case $\mathrm{SH}$ ), with a distorted or erroneous one (TOC corrected SR). Its dynamic range is [-1, 1]. The best value 1 is obtained when perfect similarity is achieved.

$$
\operatorname{SSIM}(x, y)=\frac{\left(2 \mu_{x} \mu_{y}+C_{1}\right) \cdot\left(2 \sigma_{x y}+C_{2}\right)}{\left(\mu_{x}{ }^{2}+\mu_{y}{ }^{2}+C_{1}\right) \cdot\left(\sigma_{x}{ }^{2}+\sigma_{y}{ }^{2}+C_{2}\right)}
$$

where, $x$ refers to the reference image, $y$ to the TOC corrected image, $\mu_{i}$ is the mean value of the image, and $\sigma_{i}$ the standard deviation. $\mathrm{C} 1$ and $\mathrm{C} 2$ are two user-defined constants included to avoid unstable results when $\mu_{x}{ }^{2}+\mu_{y}{ }^{2}$ and $\sigma_{x}{ }^{2}+$ $\sigma_{y}{ }^{2}$ are very close to zero. These constants are obtained from $C_{1}=\left(K_{1} \cdot L\right)^{2}$ and $C_{2}=\left(K_{2} \cdot L\right)^{2}$, where $\mathrm{L}$ is the dynamic range of the image, set to 255. In this paper values of $K_{1}=0.01$ and $K_{2}=0.03$ have been used following recommendations by Wang et al. [19].

In practice, a quantitative evaluation usually requires a single overall quality measure of the entire image [19], so a mean SSIM (MSSIM) index is used to evaluate the overall image quality of TOC corrections. Nevertheless, SSIM maps, computing the local statistics within an 11x11 circular-symmetric Gaussian weighting function, are also interesting and useful to detect problematic areas where TOC methods fail. The SSIM maps generated for each TOC corrected image show the performance of the correction pixel by pixel. 


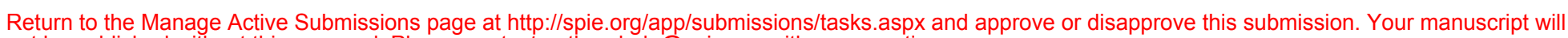
not be published without this approval. Please contact author_help@spie.org with any questions or concerns.

\section{CASE STUDY}

This study has been carried out for six different dates over the year, over a mountainous area (Pyrenees) of the NorthEastern side of Navarre, Spain. For this area a $5 \mathrm{~m}$ resolution DEM obtained through standard photogrammetric techniques is available.

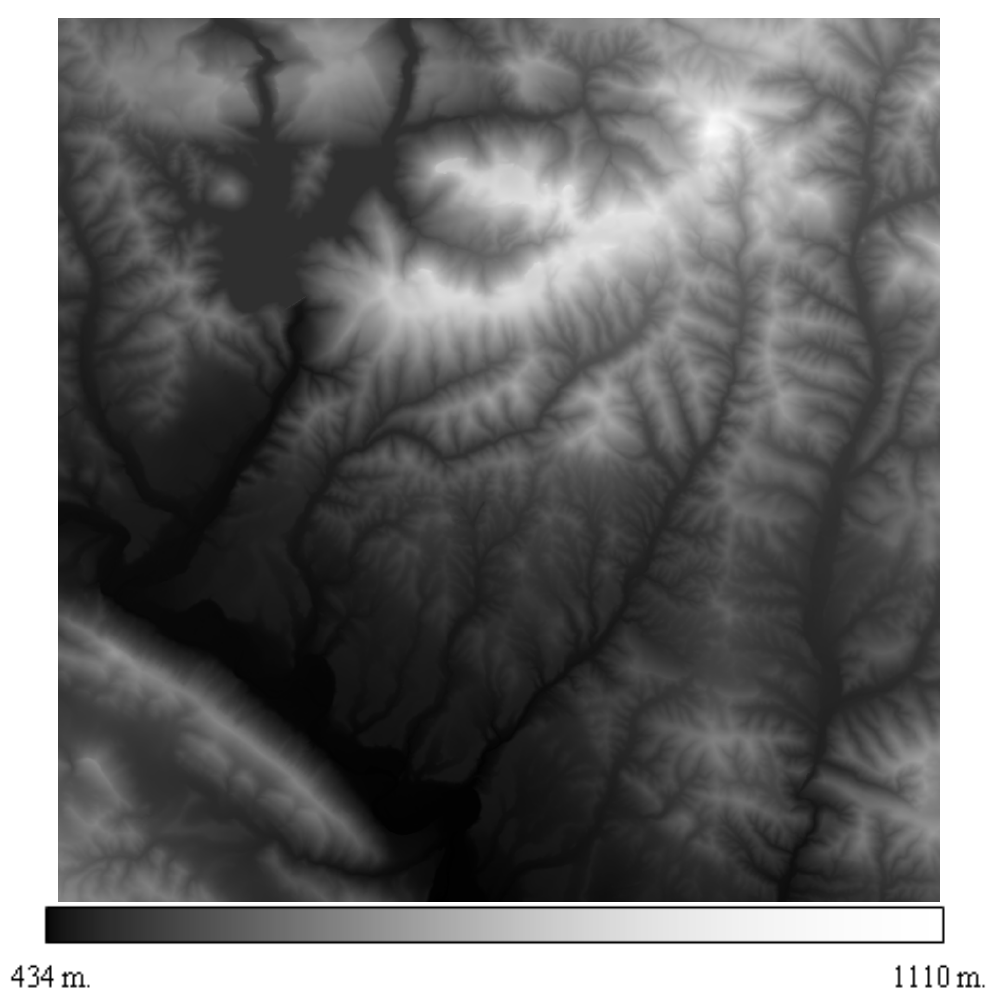

Figure 1. DEM of the study area, in the region of Navarre

Concerning the sensor configuration, a panchromatic image has been simulated with a spatial resolution of $10 \mathrm{~m}$ and a nadiral viewing angle. The land-covers' reflectance values considered for the synthetic image generation could represent either the real land-cover of the area or arbitrary values For this work, the reflectance of the real land-cover has been reproduced by using local cartography as well as spectral information from twenty different land-covers, obtained from spectral libraries of ASTER and USGS for vegetation, rocks and soil [37, 38].

This work focuses on the multitemporal evaluation of TOC methods, so scene acquisition time has been set constant to 10:45 a.m., since this is the most common acquisition time for different platforms. Solar angles do not only depend on the acquisition date but also on the time of the day. As shown in table 2, solar elevation angle is lower in winter dates, and this is one of the main causes for stronger topographic effects, due to the larger proportion of shadowed areas. Synthetic images will let us know which TOC performs better in every situation.

Table 2. Solar angles of the six different scenes simulated

\begin{tabular}{|ccccccc|}
\hline Scene & $\mathbf{1}$ & $\mathbf{2}$ & $\mathbf{3}$ & $\mathbf{4}$ & $\mathbf{5}$ & $\mathbf{6}$ \\
\hline Date & $15 / 02 / 2009$ & $15 / 04 / 2009$ & $15 / 06 / 2009$ & $15 / 08 / 2009$ & $15 / 10 / 2009$ & $15 / 12 / 2009$ \\
Time(UTC) & $10: 45$ & $10: 45$ & $10: 45$ & $10: 45$ & $10: 45$ & $10: 45$ \\
Solar azimuth angle & 153.037 & 146.104 & 132.984 & 141.349 & 159.626 & 161.345 \\
Solar elevation angle & 30.597 & 52.733 & 64.347 & 55.866 & 36.409 & 21.700 \\
\hline \multicolumn{7}{c}{} \\
\hline
\end{tabular}


Return to the Manage Active Submissions page at http://spie.org/app/submissions/tasks.aspx and approve or disapprove this submission. Your manuscript will not be published without this approval. Please contact author_help@spie.org with any questions or concerns.

Table 2 compares the solar angles obtained for the six temporal configurations chosen. With this input data the images of Global Irradiance have been calculated, and subsequently the at-sensor radiances, i.e., the final synthetic scenes, considering both the real relief of the area and a completely flat topography.

Table 3. Statistics of global irradiance in horizontal and tilted surfaces

\begin{tabular}{|c|c|c|c|c|c|c|}
\hline $\begin{array}{l}\text { Scene } \\
\text { Month }\end{array}$ & $\begin{array}{c}1 \\
\text { FEB }\end{array}$ & $\begin{array}{c}2 \\
\text { APR }\end{array}$ & $\begin{array}{c}3 \\
\text { JUN }\end{array}$ & $\begin{array}{c}4 \\
\text { AUG }\end{array}$ & $\begin{array}{c}5 \\
\text { OCT } \\
\end{array}$ & $\begin{array}{c}6 \\
\text { DEC }\end{array}$ \\
\hline \multicolumn{7}{|c|}{ GLOBAL IRRADIANCE IN HORIZONTAL SURFACE (W/m²) } \\
\hline Miniтum & 515.89 & 814.38 & 893.56 & 823.71 & 598.82 & 358.74 \\
\hline Махітит & 519.27 & 816.75 & 895.18 & 825.86 & 601.82 & 362.11 \\
\hline Mean & 517.58 & 815.56 & 894.37 & 824.79 & 600.32 & 360.43 \\
\hline$S D$ & 0.73 & 0.495 & 0.331 & 0.443 & 0.68 & 0.77 \\
\hline \multicolumn{7}{|c|}{ GLOBAL IRRADIANCE IN TILTED SURFACE $\left(\mathrm{W} / \mathbf{m}^{2}\right)$} \\
\hline Minimum & 60.72 & 73.63 & 77.62 & 79.07 & 68.39 & 48.52 \\
\hline Maximum & 1023.59 & 1161.61 & 1155.27 & 1136.55 & 1050.64 & 931.51 \\
\hline Mean & 509.54 & 806.41 & 882.13 & 814.33 & 593.30 & 353.62 \\
\hline$S D$ & 171.75 & 131.63 & 95.61 & 118.90 & 164.24 & 165.50 \\
\hline \multicolumn{7}{|c|}{$\begin{array}{l}\text { Based on table } 3 \text {, the following observations are noted. On the one hand, scenes acquired in summer months result in } \\
\text { more irradiance impinging on the surface, but at the same time lower standard deviation (SD), due to less severe } \\
\text { topographic effects. On the other hand, winter scenes, i.e. scenes } 1,5 \text { and } 6 \text { corresponding to February, October and } \\
\text { December, have lower radiance values but higher variance due to more severe topographic effects, caused by lower solat } \\
\text { elevation angles. }\end{array}$} \\
\hline \multicolumn{7}{|c|}{ Table 4. Statistics of the synthetic scenes } \\
\hline Scene & 1 & 2 & 3 & 4 & 5 & 6 \\
\hline Month & FEB & APR & JUN & AUG & OCT & $\mathrm{DEC}$ \\
\hline \multicolumn{7}{|c|}{ AT-SENSOR RADIANCE - SYNTHETIC HORIZONTAL (SH) IMAGE (W/m². sr.) } \\
\hline Minimum & 18.33 & 27.33 & 31.57 & 30.12 & 19.93 & 13.54 \\
\hline Махітum & 163.21 & 253.13 & 278.50 & 258.27 & 187.34 & 115.33 \\
\hline Mean & 81.89 & 126.35 & 139.85 & 130.17 & 93.34 & 58.19 \\
\hline$S D$ & 22.13 & 34.45 & 37.66 & 34.80 & 25.56 & 15.56 \\
\hline \multicolumn{7}{|c|}{ AT-SENSOR RADIANCE - SYNTHETIC REAL (SR) IMAGE (W/m². sr.) } \\
\hline Minimum & 18.28 & 27.29 & 31.52 & 30.07 & 19.88 & 13.49 \\
\hline Maximum & 219.19 & 287.32 & 298.43 & 287.37 & 236.49 & 181.96 \\
\hline Mean & 81.68 & 126.04 & 139.09 & 129.66 & 93.28 & 58.05 \\
\hline$S D$ & 30.46 & 39.18 & 40.81 & 38.93 & 32.80 & 25.13 \\
\hline $\begin{array}{l}\text { The statistics } \\
\text { the summer } n \\
\text { values in both } \\
\text { effects in } \mathrm{SH} \\
\text { between } \mathrm{SH} \text { a } \\
\text { severe topogr }\end{array}$ & $\begin{array}{l}\text { thetic scen } \\
\text { also higher } \\
\text { ind SR, due } \\
\text { is results ir } \\
\text { R scenes, } \mathrm{c} \\
\text { effects, the }\end{array}$ & $\begin{array}{l}\text { ble } 4 \text { shou } \\
\text { sor radian } \\
\text { influence } \\
\text { variance } \\
\text { he effect o } \\
\text { higher corr }\end{array}$ & $\begin{array}{l}\text { llowing: 1) } \\
\text { es. 2) Unl } \\
\text { ntroduced } \\
\text { those ima } \\
\text { traphy in th } \\
\text { to be done }\end{array}$ & $\begin{array}{l}\text { values of } \\
\text { oal irradia } \\
\text { vers' refle } \\
\text { apared wit } \\
\text { r, is highe } \\
\text { algorithn }\end{array}$ & $\begin{array}{l}\text { ce impingi } \\
\text { final scer } \\
\text { 3) The abs } \\
\text { cenes 4) } \mathrm{T} \\
\text { inter scene }\end{array}$ & $\begin{array}{l}\text { he surface } \\
\text { e higher S } \\
\text { topograph } \\
\text { rence in } \mathrm{S} \\
\text { means mor }\end{array}$ \\
\hline
\end{tabular}


Please verify that (1) all pages are present, (2) all figures are correct, (3) all fonts and special characters are correct, and (4) all text and figures fit within the red margin lines shown on this review document. Complete formatting information is available at http://SPIE.org/manuscripts

Return to the Manage Active Submissions page at http://spie.org/app/submissions/tasks.aspx and approve or disapprove this submission. Your manuscript will not be published without this approval. Please contact author_help@spie.org with any questions or concerns.

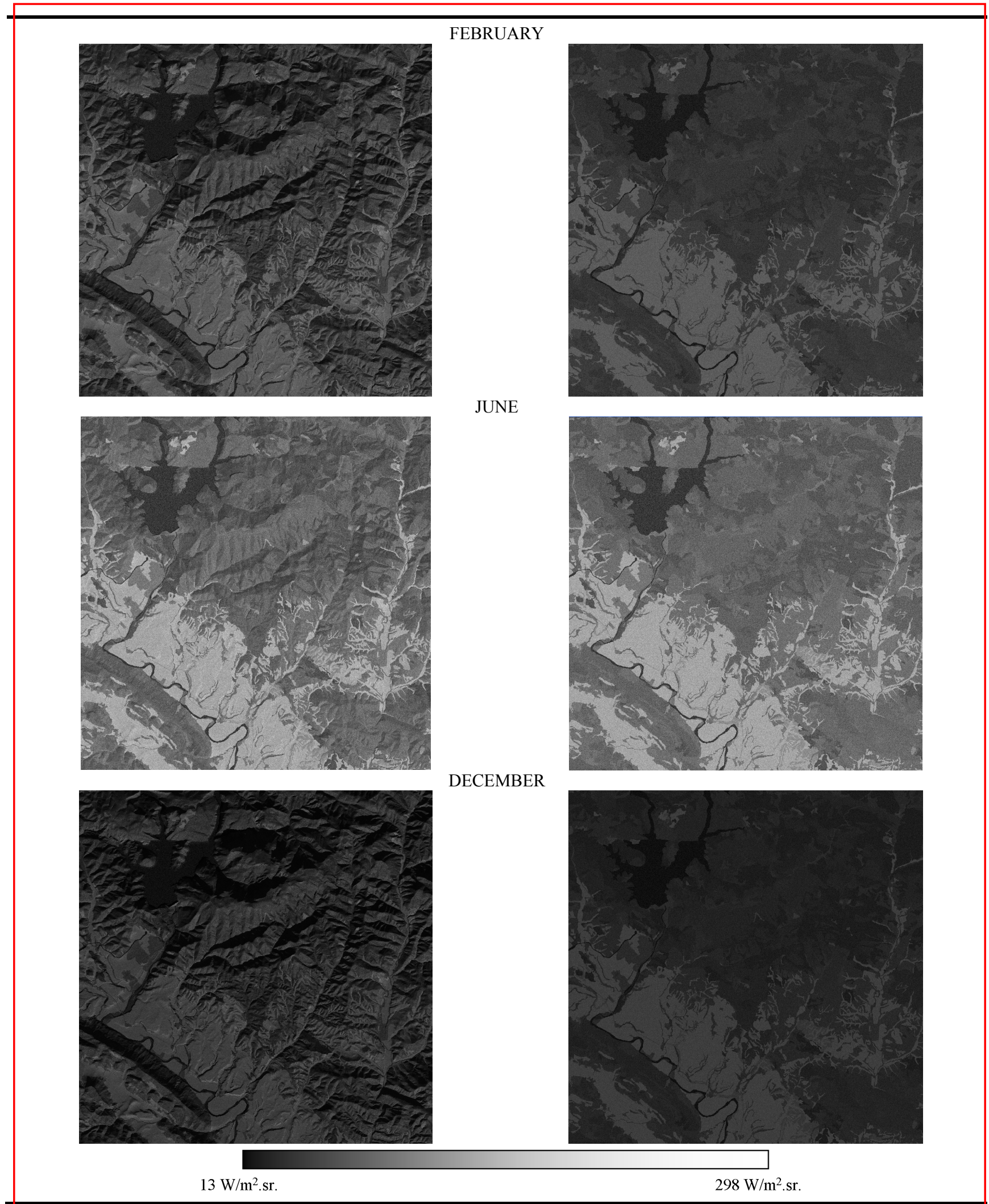

Figure 2. Some samples of synthetic scenes obtained. On the left, synthetic real (SR) scenes, and on the right, synthetic horizontal (SH) scenes for three different dates. 
Return to the Manage Active Submissions page at http://spie.org/app/submissions/tasks.aspx and approve or disapprove this submission. Your manuscript will not be published without this approval. Please contact author_help@spie.org with any questions or concerns.

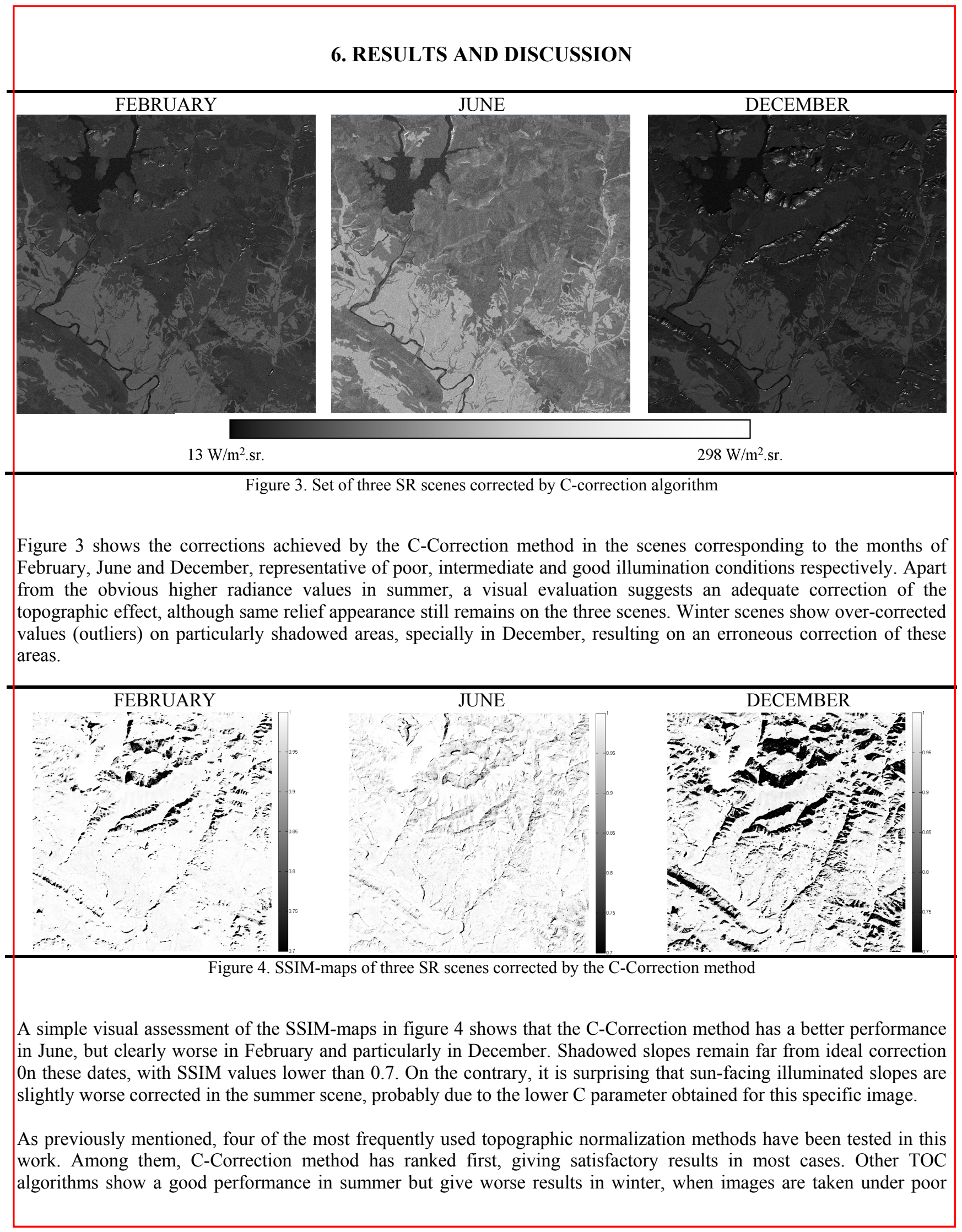


Return to the Manage Active Submissions page at http://spie.org/app/submissions/tasks.aspx and approve or disapprove this submission. Your manuscript will not be published without this approval. Please contact author_help@spie.org with any questions or concerns.

illumination conditions. On the contrary, it can be observed that the simplest method tested, the Cosine correction, gives clearly poorer results than some of the other methods, especially in winter images.

The MSSIM values scored by the six non-corrected scenes show how intense the topographic effect is for each date, and can be used as a reference. Winter scenes (February, October and December) score MSSIM values lower than 0.90, which corresponds to a low similarity with the ideal correction, due to the topographic effect. The Cosine method yielded slightly higher MSSIM values, and not even that in the December scene, so this method is not recommended. As shown in figure 5, summer scenes are well-corrected with the four TOC methods tested, with little differences between them, but differences increase as solar elevation angles decrease.

In these unfavourable dates, i.e. February, October and December, C-Correction method performs clearly better than other algorithms. In this case, winter MSSIM values are also lower than those of summer scenes. But in the worst case, a MSSIM above 0.87 is obtained. The Enhanced Minnaert and Empiric-Statistical methods offer an intermediate performance, with the latter being slightly worse in general (except for December).

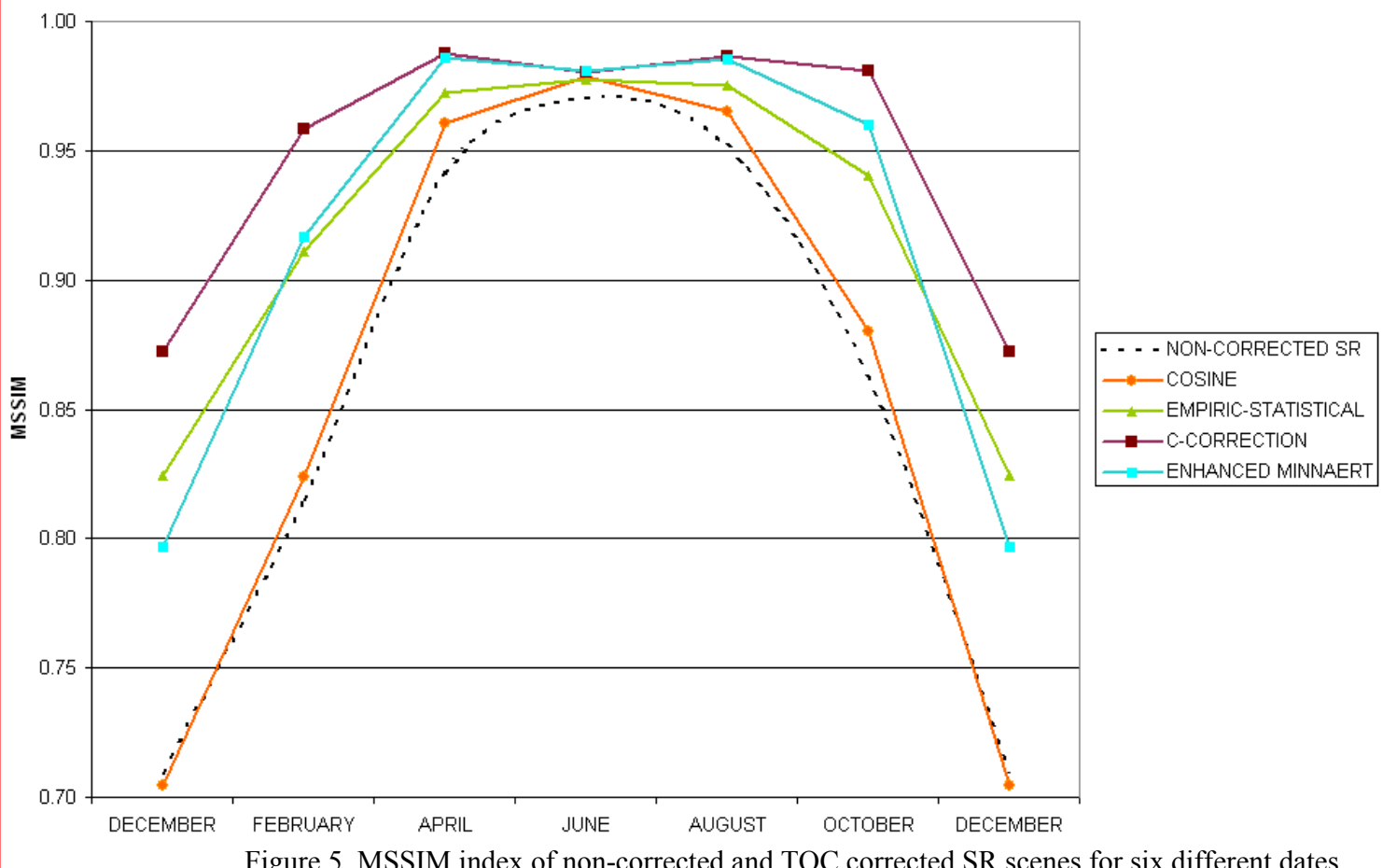

\section{CONCLUSIONS}

We can conclude here that there is a strong influence of the acquisition date on the performance of TOC methods, due to different illumination conditions. So, TOC methods do not perform the same over the year. In summer months topographic effects are softer, so the differences between TOC methods are lower, since there is less to correct. On the contrary, more severe topographic effects in winter dates results in larger differences between TOC methods as there is much more to correct. Any of the four tested TOC methods failed to completely remove the topographic effect in these extreme conditions.

Winter scenes showed clear differences between TOC algorithms, being C-Correction the one that ranks first. Our results are in line with results obtained by other authors [18], indicating the worse performance of Cosine method, while Enhanced Minnaert method also performs a poor correction, specially in winter scenes.

Finally, this paper shows how synthetic images could be used to evaluate in detail TOC algorithm performance, in particular their behaviour during the year. The scene simulator and the SSIM index application have been proved 
Return to the Manage Active Submissions page at http://spie.org/app/submissions/tasks.aspx and approve or disapprove this submission. Your manuscript will not be published without this approval. Please contact author_help@spie.org with any questions or concerns.

effective in order to assess the goodness of topographic corrections under specific conditions. The method proposed offers a means of generating synthetic scenes acquired under a variety of settings and acquisition configurations (i.e. solar angles, spatial resolution...). Accordingly, the influence of each configuration parameter on the performance of the TOC methods can be evaluated. Obviously, this approach assumes that a TOC showing a good performance for synthetic imagery also performs correctly for real imagery with similar acquisition configuration. In the future this approach could be used to analyse the influence of land-cover spatial variability on the performance of TOC algorithms and also the influence of sensor configuration.

\section{REFERENCES}

[1] Soenen, S. A., Peddle, D. R., and Coburn, C. A., "SCS+C: A modified sun-canopy-sensor topographic correction in forested terrain," IEEE Transactions on Geoscience and Remote Sensing, 43(9), 2148-2159 (2005).

[2] Teillet, P. M., Guindon, B., Goodenough, D. G., "On the slope-aspect correction of multispectral scanner data.," Canadian Journal of Remote Sensing, 8(2), 84-106 (1982).

[3] Ekstrand, S., "Landsat TM-based forest damage assessment: Correction for topographic effects," Photogrammetric Engineering and Remote Sensing, 62(2), 151-161 (1996).

[4] Tokola, T., Sarkeala, J., and Van der Linden, M., "Use of topographic correction in Landsat TM-based forest interpretation in Nepal," International Journal of Remote Sensing, 22(4), 551-563 (2001).

[5] Zhan, X., Sohlberg, R. A., Townshend, J. R. G. et al., "Detection of land cover changes using MODIS $250 \mathrm{~m}$ data," Remote Sensing of Environment, 83, 336-350 (2002).

[6] Vicente-Serrano, S. M., Pérez-Cabello, F., and Lasanta, T., "Assessment of radiometric correction techniques in analyzing vegetation variability and change using time series of Landsat images," Remote Sensing of Environment, 112(10), 3916-3934 (2008).

[7] Lu, D. S., Ge, H. L., He, S. Z. et al., "Pixel-based Minnaert Correction Method for Reducing Topographic Effects on a Landsat 7 ETM+ Image," Photogrammetric Engineering and Remote Sensing, 74(11), 1343-1350 (2008).

[8] Civco, D. L., “Topographic Normalization of Landsat Thematic Mapper Digital Imagery,” Photogrammetric Engineering and Remote Sensing, 55(9), 1303-1309 (1989).

[9] Meyer, P., Itten, K. I., Kellenberger, T. et al., "Radiometric Corrections of Topographically Induced Effects on Landsat Tm Data in an Alpine Environment," ISPRS Journal of Photogrammetry and Remote Sensing, 48(4), 17-28 (1993).

[10] Riano, D., Chuvieco, E., Salas, J. et al., "Assessment of different topographic corrections in Landsat-TM data for mapping vegetation types," IEEE Transactions on Geoscience and Remote Sensing, 41(5), 1056-1061 (2003).

[11] Baraldi, A., Gironda, M., and Simonetti, D., "Operational Two-Stage Stratified Topographic Correction of Spaceborne Multispectral Imagery Employing an Automatic Spectral-Rule-Based Decision-Tree Preliminary Classifier," IEEE Transactions on Geoscience and Remote Sensing, 48(1), 112-146 (2010).

[12] Smith, J. A., Lin, T. L., and Ranson, K. J., "The Lambertian Assumption and Landsat Data," Photogrammetric Engineering and Remote Sensing, 46(9), 1183-1189 (1980).

[13] Gu, D., and Gillespie, A., "Topographic normalization of landsat TM images of forest based on subpixel Suncanopy-sensor geometry," Remote Sensing of Environment, 64(2), 166-175 (1998).

[14] Itten, K. I., Meyer, P., Kellenberger, T. et al., "Radiometric and Geometric Correction of Tm-Data of Mountainous Forested Areas," International Space Year : Space Remote Sensing, Vols 1 and 2, 1650-1652 (1992).

[15] Conese, C., Gilabert, M. A., Maselli, F. et al., "Topographic Normalization of Tm Scenes through the Use of an Atmospheric Correction Method and Digital Terrain Models," Photogrammetric Engineering and Remote Sensing, 59(12), 1745-1753 (1993).

[16] Zhang, W. C., and Gao, Y. N., "LULC Classification and Topographic Correction of Landsat-7 ETM+ Imagery in the Yangjia River Watershed: the Influence of DEM Resolution," Sensors, 9(3), 1980-1995 (2009).

[17] Shepherd, J. D., and Dymond, J. R., "Correcting satellite imagery for the variance of reflectance and 
Return to the Manage Active Submissions page at http://spie.org/app/submissions/tasks.aspx and approve or disapprove this submission. Your manuscript will not be published without this approval. Please contact author_help@spie.org with any questions or concerns.

illumination with topography," International Journal of Remote Sensing, 24(17), 3503-3514 (2003).

[18] Hantson, S., and Chuvieco, E., "Evaluation of different topographic correction methods for Landsat imagery," International Journal of Applied Earth Observation and Geoinformation, 13 691-700 (2011).

[19] Wang, Z., Bovik, A. C., Sheikh, H. R. et al., "Image Quality Assessment: From Error Visibility to Structural Similarity," IEEE Transactions on Image Processing, 13(4), 600-612 (2004).

[20] Sola;, I., Audícana;, M. G. d., Álvarez-Mozos;, J. et al., "Utilidad de las imágenes sintéticas para la determinación de la bondad de distintos algoritmos de corrección topográfica.," AET Congress (Mieres, Spain), (2011).

[21] Hottel, H. C., and Whiller, A., "Evaluation of fiat plate solar collector performance," Transcription of the Conference on Use of Solar Energy, The Scientific Basis, II(I (Section A)), 74 (1958).

[22] Liu, B. Y. H., and Jordan, R. C., "The interrelationship and characteristic distribution of direct, diffuse and total solar radiation," Solar Energy, 4(1), (1960).

[23] Ma, C. C. Y., and Iqbal, M., "Statistical comparison of solar radiation correlation-monthly average global and diffuse radiation on horizontal surfaces," Solar Energy, 33(143), (1984).

[24] ASHRAE, "ASHRAE Handbook of Fundamentals," American Society of Heating, Refrigeration and Airconditioning Engineers, (1985).

[25] Kasten, F., "The Linke turbidity factor based on improved values of the integral Rayleigh optical thickness.," Solar Energy, 56(3), 239-244 (1996).

[26] Page, J., "Algorithms for the Satellight programme," Technical Report for the second SATELLIGHT meeting in Bergen, Norway, (1996).

[27] Dumortier, D., "Mesure, analyse et modélisation du gisement lumineux. Application à l'évaluation des performances de l'éclairage naturel des bâtiments.," PhD Thesis, Université de Savoie, France., (1995).

[28] Dumortier, D., "The satellight model of turbidity variations in Europe " Report for the sixth SATELLIGHT meeting in Freiburg, Germany., (1998).

[29] Ineichen, P., "Radiation Derivation from Meteosat Counts " Group of Applied Physics, University of Geneva(Report for the sixth SATELLIGHT meeting in Freiburg, Germany), (1998).

[30] Richter, R., "Correction of satellite imagery over mountainous terrain," Applied Optics, 37, 4004-4015 (1998).

[31] Hay, J. E., and McKay, D. C., "Estimating solar irradiance on inclined surfaces: a review and assessment of methodologies," International Journal of Solar Energy, 3, 230 - 240 (1985).

[32] Sandmeier, S., and Itten, K. I., "A Physically-Based Model to Correct Atmospheric and Illumination Effects in Optical Satellite Data of Rugged Terrain," IEEE Transactions on Geoscience and Remote Sensing, 35(3), 708717 (1997).

[33] Bird, R. E., and Hulstrom, R. L., "A simplified clear sky model for direct and diffuse insolation on horizontal surfaces," Report SERI, TR-642-761, (1981).

[34] Gilabert, M. A., Conese, C., and Maselli, F., "An Atmospheric Correction Method for the Automatic Retrieval of Surface Reflectances from Tm Images," International Journal of Remote Sensing, 15(10), 2065-2086 (1994).

[35] Sola;, I., Audícana;, M. G. d., Álvarez-Mozos;, J. et al., "Synthetic images for evaluating Topographic Correction Algorithms," Submitted to IEEE Transactions on Geoscience and Remote Sensing, (2012).

[36] Minnaert, M., "The reciprocity principle in lunar photometry," Astrophysical Journal, 93(3), 403-410 (1941).

[37] Baldridge, A. M., Hook, S. J., Grove, C. I. et al., "The ASTER spectral library version 2.0," Remote Sensing of Environment 113, 711-715 (2009).

[38] Clark, R. N., Swayze, G. A., Wise, R. et al., "USGS digital spectral library splib06a: U.S. Geological Survey, Digital Data Series 231," (2007). 